\title{
Effect of Pulsed Magnetic Field Therapy on Pain in Children with Acute Burn Injury
}

\author{
ELHAM E. SALEM, Ph.D.*; ASMAA O. SAYED, Ph.D.*; \\ AMIRA E. ABD EL-MAGEID, M.Sc.* and AYMAN NOAMAN, M.D.** \\ The Departments of Physical Therapy for Pediatrics, Faculty of Physical Therapy*, Cairo University and \\ Plastic Surgery, Faculty of Medicine, Cairo University**
}

\begin{abstract}
Background: Pain management is essential in burn injury for children to better out come during all stages of treatment and rehabilitation.

Aim of Study: Was to determine effect of pulsed magnetic therapy on pain in children after second degree of burn.

Subjects and Methods: We have utilized children with acute burn injury, experimental design study, randomized, convenate on forty child, subjects divided into two group, control group (A) received specific design physical therapy program me and study group (B) received specific design physical therapy program me in addition to pulsed magnetic field therapy. Pulsed electromagnetic therapy application 3 days weekly, 20 minutes every session received pulsed electromagnetic field. Pain was assessed with Wong backer faces pain scale in both groups after three days of injury and after three weeks of injury results. There were significant decrease in pain post application of pulsed electromagnetic field compared to its pre application, there was significant decrease in pain, post application of specific design physical therapy programme compared to its pre application and a significant decrease in the pain of study group compared with that of control group post-treatment $(p=0.0001)$.

Conclusions: The present study demonstrate that pulsed electromagnetic field justify amount of improvement in pain relieve in acute burn injury.
\end{abstract}

Key Words: Pulsed magnetic field therapy - Acute painBurn children.

\section{Introduction}

MAGNETIC therapy is non invasive, simple and save techniques, often administer over the site of a painful injury or inflammation, it has been used for indication for centuries, and claims of analgesic efficacy have been made. And can be used in outpatient or at home [1]

Correspondence to: Dr. Elham E. Salem,

The Department of Physical Therapy for Pediatrics,

Faculty of Physical Therapy, Cairo University
The treatment outcome affecting pain perception was achieved both directly and indirectly direct effects of magnetic fields are; neuron firing, calcium ion movement membrane potential, endorphin levels, nitric oxide, dopamine levels, acupuncture actions and nerve regeneration. Indirect benefits of magnetic fields on physiological function effect; circulation, muscle, edema, tissue oxygen prostaglandin, inflammation, healing cell cellular metabolism and cell energy levels [2].

One of probable mechanisms of PEMFs pain relieve may be to modulate the cell membrane potential. Normal cell potential is about $90 \mathrm{MV}$ (mille volt), while in inflammatory and degenerative condition, cell potential is about $120 \mathrm{MV}$ and $30 \mathrm{MV}$, respectively. PEMFs were found to depolarize neurons to enable these neurons to reach on action potential releasing chemical signal materials which result in pain de sensitization [3].

Children with burn injuries suffer from severe pain at time of the burn and during treatment and rehabilitation. Pain has adverse physiology and emotional effects and slows down the functional recovery process. Pain management is essential to better out comes during all stages of treatment and rehabilitation [4].

Behavioral observation largely been developed to assess pain in infants and young children. Self report measure is usually used for children above the age of four but they do require sufficient cognitive and language abilities to be accurate. $\mathrm{Nu}-$ merous visual analogue instruments have been developed which ask children to describe their pain on continuum of intensity along a line using numerical anchors [5]. Visual analogue scales are widely used, have good psychometric properties and are easily administered to children [6] . 
The Wong Baker faces scale $(0-10)$ is preferred for the pediatric population because younger or no English speaking children can understands the duplicated pain emotions [7]. The purpose of this study was to determine effect of pulsed magnetic therapy on pain after second degree of burn in children.

\section{Subjects and Methods}

\section{The study population:}

Forty patient children suffer from burn (21 boys and 19 girls) aged from 3-5 years old and recruited from Burn Unit of Beni Seuif Hospital. After obtaining approval of Hospital Ethics Committee and informed consent from the included patients. They were divided into 2 main groups: Group A (control group) formed of 20 received the specific design of physical therapy programme has been applied (positioning, splinting and mobilization (active, passive range of motion exercises). Group B (study group) formed of 20 received (PEMF) has been applied in addition to specific physical therapy programme. The study was conducted from November 2015 to April 2018.

They were enrolled in this study according to the following:

A- Inclusion criteria:

1- All children diagnosed had second degree of burn.

2- The area of injury was ranged from 2.5 to $40 \%$ of Total Body Surface Area (TBSA).
3- Involvement of one or both hands and one or both arms and forearms.

\section{B- Exclusion criteria:}

The patients were excluded if they met any one of the following criteria:

1- Patient who had any neurological or orthopedic disorder.

2- Patient who had any vascular disorders and diabetes mellitus.

3- Patients who required skin graft for hand or area affected during the period of study.

4- Children who had electrical and chemical burn.

5- Children who had myasthenia gravis, hyperthyroidism, active bleeding, acute viral disease, acute tuberculosis mental disorders or those with pacemaker.

\section{Pain assessment:}

Pain was assessed using Wong Baker Faces Pain Rating Scale the third day of injury and after three weeks. The scale shows a series of faces ranging from a happy face at 0 , "no hurt" to a crying face at 10 "hurts worst". The patient must choose the face that best describes how they are feeling [8]

The card with the faces was showed to the children and explained to them that each face is for a person who feel happy. Because he has no pain (hurt) or sad because he has some or a lot of pain. Point to each face and say what it means. As shown in Fig. (1).

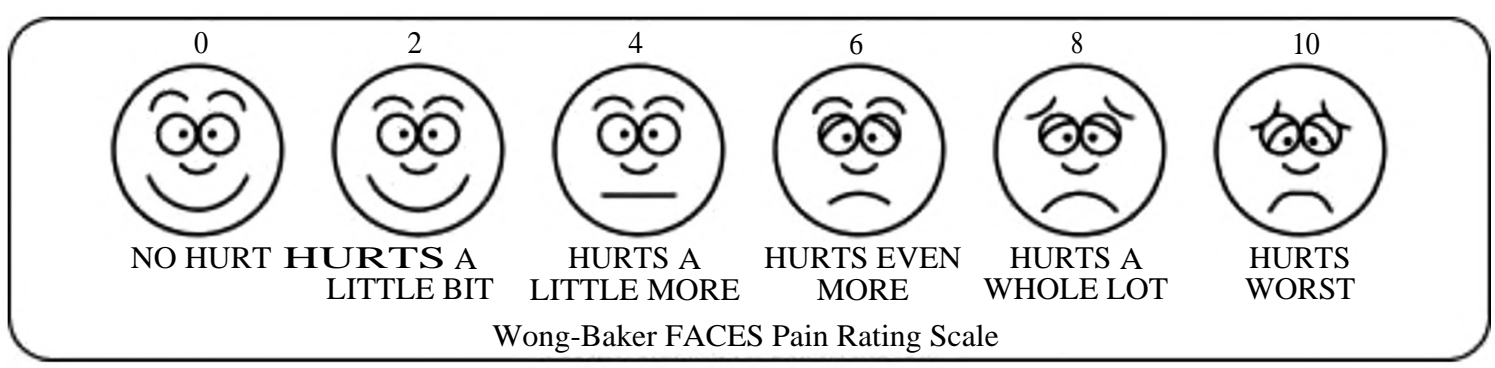

Fig. (1): Wong-Baker Faces Pain Rating Scale (WBFPS).

Pulsed electromagnetic field therapy application:

Twenty patients, who was received specific design of physical therapy program in addition to pulsed magnetic therapy devices, Easy Teraza Serie (ETS), 2011, code F9020087 and 230 voltage.

The treatment was started 72 hours after injury and was continued day after day for three weeks 20 minutes every session received (PEMF). Frequency $50 \mathrm{HZ}$, the child was rested supine on manual bed. The therapist was pulled a portable solenoid to cover the affected area. During treatment, patient must not wear metal objects or anything sensitive to magnetic field, such as chains and belts.

\section{Statistical analysis:}

Statistical analysis of the data was collected, coded and entered to computer. The data was analyzed with the program (SPSS) statistical package for social science Version 19 under windows 8. Data comparisons were performed using paired $t$-test. The levels of significance were accepted 
with $p<0.05$ and all relevant results were. Graphically displayed as mean $\pm \mathrm{SD}$.

\section{Results}

The purpose of this study was to investigate the effect of pulsed magnetic therapy on pain after second degree burn in children In this study, it was found that, there was no significant difference in the scoring of WBFPS between control and study groups pre-treatment ( $p=0.76)$, a significant decrease in the WBFPS of control group posttreatment compared with pre treatment $(p=0.0001)$, a significant decrease in the WBFPS of study group post-treatment compared with pre-treatment ( $p=$ $0.0001)$. And there was a significant decrease in the WBFPS of study group compared with that of control group post-treatment $(p=0.0001)$. As shown in (Table 1) and Fig. (2).

Table (1): The WBFPS values, pre and post application of SPSP and PEMF on both group.

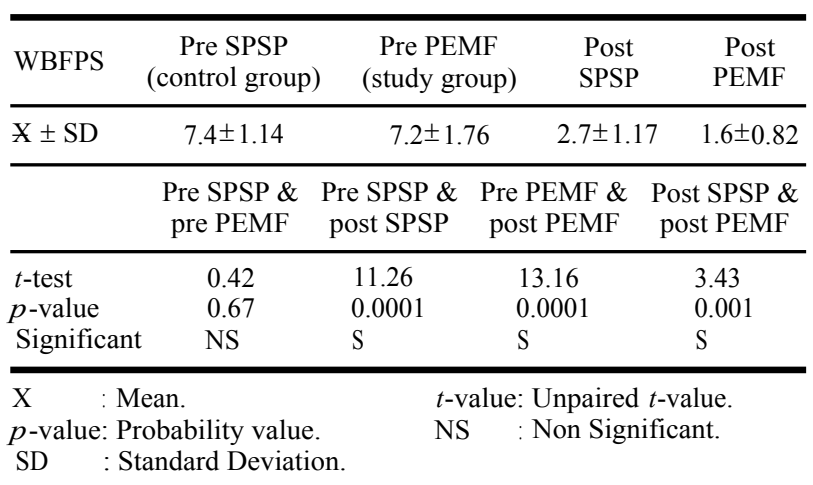

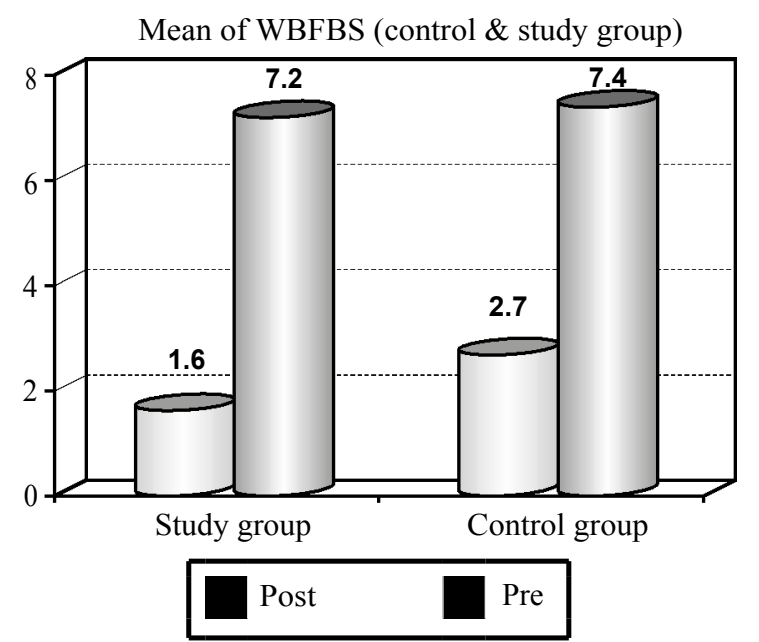

Fig. (2): The mean of WBFPS pre and post application of SPTP and PEMF on Both groups.

\section{Discussion}

The development of more effective methods of relieving pain associated with burn injury is a major unmet medical need. Various types of mag- netic and electromagnetic fields are now in successful use in modern medicine. Electromagnetic therapy carries the promise to heal numerous health problems, even where conventional medicine has failed. Today, magnetic therapy provides non invasive, safe, and easy method to directly treat the site of injury, the source of pain and inflammation and variety of diseases' and pathologies [9].

In the current study Wong backer faces pain rating scale were used as a measurement of pain as it considered the most valid scale for age ranged from 3 to 5 years. This come in agreement with (Khatri A and Kalra N, 2012) [10]. Their study finding supports the utility of obtaining child selfreport of pain and shows that both Visual Analogue Scale (VAS) and Wong-Baker Faces Pain Rating Scale (WBFPS) scale were appropriate tools used for assessment of pain among children aged 3 to 14 year.

In the present study, we demonstrate an effect of PEMF on pain sensation in an acute burn injury in pediatric that concurrent with two previous studies investigating the effect of PMFT on clinical muscular pain in humans have demonstrated an analgesic effect, even after only one treatment $[11,12]$ used the same technique of magnetic stimulation using a $20 \mathrm{~Hz}$ pulse of PMFT of variable but high intensity (up to 4000 Gauss). In contrast with studies which investigate effect of the PEMF on acute muscle pain for $30 \mathrm{~min}$ in a randomized order delivered by two identical, commercially available machines (Pulse Pack 6000 Quantum Techniks). The active machine delivered a $\mathrm{M}$-wave magnetic pulse $(1.25 \mathrm{~Hz}, 3 \mathrm{~ms}$ width, 600 Gauss. [13], and Shupak et al., [14]. The study investigated the potential analgesic benefit of MF exposure on sensory and pain thresholds following experimentally induced warm and hot sensations. His results indicated that MF exposure does not affect basic human perception, but can increase pain thresholds in a manner indicative of an analgesic response. Our study has several limitations. We have focused on pain scores; we did not investigate other potentially important clinical effects of PMFT. When compared with other studies. However, the duration of the application was that recommended by the manufacturer and is in common clinical use. Finally, we did not investigate the effect of different magnetic parameters.

In conclusion, we were demonstrated an analgesic effect of PMFT in our study. Further work is required to elucidate the effects of different field strengths pulse widths, and frequencies. 


\section{Ethical approval:}

The Research Committee at faculty of Physical Therapy Cairo University, Burn Unit of Beni Seuif Hospital after obtaining approval of Hospital Ethics Committee, and informed consent from the included patients. Approved this study (20/11/015).

\section{References}

1- FINEGOLD L. and FLAMN B.: Magnet therapy: Extraordinary claims, but not proven benefit. Br. Med. J., 332: 4, 2006.

2- YADOLLAHPOUR A. and RASHIDI S.: " Electromagnetic field as a pain relieving modality: "A review of the current literature. International Journal of Green Pharmacy, 11 (1): S76, 2017.

3- TIKTINSKY R., CHEN L. and NARAAYON P.: "Electrotherapy: Yesterday, today and Tomorrow. National Hemophilia Center, 16 (5): 126-31, 2010.

4- SHOHEI OHGI and SHOUZHI U.: "Pediatric burn rehabilitation: Philosophy and strategies. Burn and trauma, 1 (2): 73-9, 2013.

5- STODDARD D., R.L. SHERDIAN, et al.: "Treatment of pain in acutely burned children. Journal of the Burn and Rehabilitation, 23 (2): 135-56, 2002.

6- SU MMER J., PUNTILLO A., GREEN G. and LEVINE D.: Burn injury paint the counting challenge of pain, 8: 33-48, 2007.
7- RICHARDSON P. and MASTARD E.: "The management of pain in the burns unit, 35: 921-36, 2009.

8- COTÉ, CHARLES J., JERROLD LERMAN I. and DAVID TODRES: "A practice of anesthesia for infants and children. Elsevier Health Sciences p. 940. ISBN 978-1-41603 134-5, 2009.

9- MARKO S. MARKOV: "Expanding Use of Pulsed Electromagnetic Field Therapies Electromagnetic Biology and Medicine, 26 (3): 257-74, 2009.

10- KHATRI A. and KALRA N.: "A Comparison of Two Pain Scales in the Assessment of Dental Pain in East Delhi Children. International Scholarly Research Network ISRN Dentistry, Article ID 247351, 2012.

11- PUJOL J., PASCUAL A., et al.: "The effect of repetitive magnetic stimulation on localized musculoskeletal pain. Neuroreport., 9: 1745-8, 1998.

12- SMANIA N., CORATO E., FIASCHI A., et al.: "Therapeutic effects of peripheral repetitive magnetic stimulation on myofascial pain syndrome. Clin. Neurophysiology, 114: 350-8, 2003.

13- FERNANDEZ I, WATSON J. and ROWBOTHOM.: "Effect of pulsed magnetic field therapy on pain reported by human volunteers in a laboratory model of acute pain. British Journal of Anesthesia, 99 (2): 266-9, 2007.

14- SHUPAK M., PRATO S. and THOMAS W.: "Human exposure to a specific pulsed magnetic field: Effects on thermal sensory and pain thresholds. Neurosci Lett., 363 (2): 157-62, 2004.

\section{تآثير المجال الكهرومغناطيسي النابض على الآلم فى الحروق لدى الآطفال}

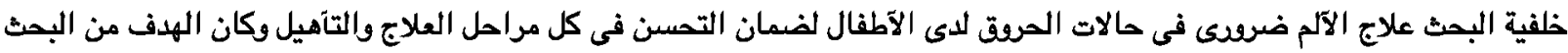

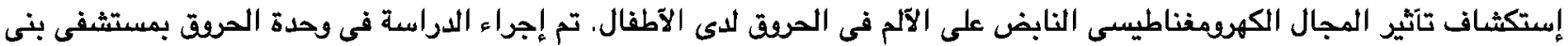

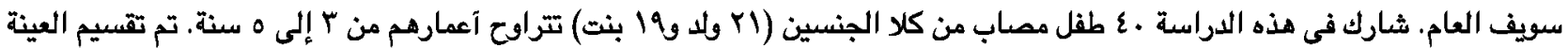

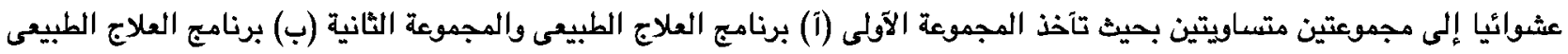

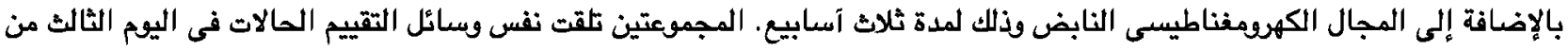

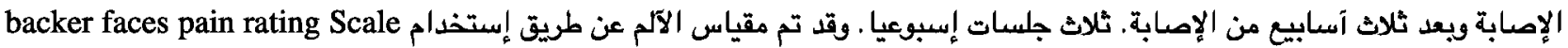

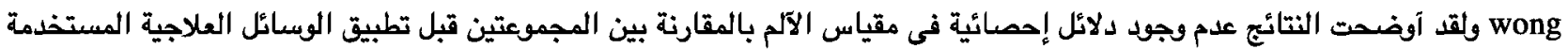

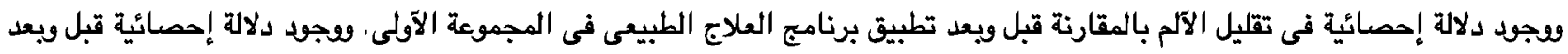

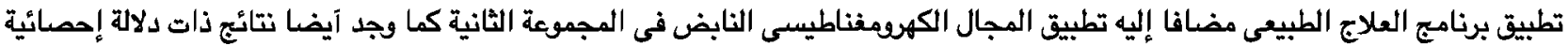

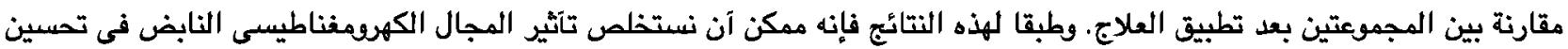
الآلم في الحرق الصادة للآطفال. 